\title{
Original Research Study \\ Studies on Components, Challenges, Attitude and Expertise in Teaching Digital Rectal Examination(DRE) Skill to final MBBS Medico's in Kingdom of Saudi Arabia and Republic of India
}

\author{
Shashi Shekhar \\ Associate Professor, Department of General Surgery, Saraswathi Institute of Medical Sciences, \\ Anwarpur, Hapur-NCR, India
}

\begin{abstract}
In the present study on MBBS final year Students in Kingdom of Saudi Arabia and India

(1). Knowledge of Steps of DRE was present in 77.67\% of Male medico's and $86.49 \%$ of Female medico's. Only $10.67 \%$ Males and 5.76\% of Females medico's did not do any DRE ; However 36.89\% of Male students and $27.58 \%$ of Female students were not supervised by Senior Faculty .

(2). Communication Skill was present in $75.72 \%$ of Male and $47.12 \%$ of Female medico's. (3). Disease Correct Diagnosis Skill was present in $92.23 \%$ of Males \& $94.25 \%$ of Female medico's.
\end{abstract}

Keywords: Intimate physical examinations, Digital rectal examination.

\section{Background}

Process of physical examinations of intimate organs like genitalia, rectum, perineum and breast, is greatly complicated.

Challenges in teaching DRE skill are related to Teacher, Patient, Medical Student and Approach.

Digital rectal examination (DRE) helps detection of abnormalities of the rectum and prostate. Rectal Cancer, Rectal Polyp \&Prostate Enlargement-BPH, Prostate Nodule, Prostate Cancer. 1,2,3,4

Concern has arisen in World over and over- seas that medical students are no longer acquiring the skill of DRE before they graduate. DRE in a clinical setting, doctors are not sufficiently supervised by senior physicians .

\footnotetext{
Corresponding Author

Shashi Shekhar

Laparoscopic Surgeon \& Andrologist

Men's Health Clinic , Pinnacle Tower B-305, Indirapuram-Ahinsa Khand 2, Ghaziabad-201014, UP-NCR, India. Email: drdrshashishekhar@gmail.com

TEL: +91-9989691292
}

In the United Kingdom, number of DREs performed by medical students is falling ${ }^{3}, 11-30$ (1990); 03-05 $(2000)^{5,6} \cdot$ In Australia," Of the 222 students, 92\% accepted DRE had been taught how to perform a DRE, and $81 \%$ had received a tutorial on the DRE technique using plastic models.

\section{Challenges in Teaching Dre Skill}

\section{Socio Ethics related ${ }^{8,9}$}

1. It involves teaching on private part of patient,

2. Position for DRE needs patients cooperation 3. Real patients are sometimes unfit or unwilling

Patient related:

1. Unwillingness, 2. Resentfulness and unwillingness, 3.Real patients Concern, and expectations related to diagnosis and treatment, 4.Real patients Pain, bleed and discomfort and being too sick, 5. Being only for the benefit of Medical students

\section{Medical Student related ${ }^{6}$ :}

1. Student may be embarrassed or anxious, 2. Practice opportunities are less, only sporadic or opportunistic,3. DRE requires informed consent and 
appropriate supervision.,

4. Students may be more comfortable with old, child or rural patient.

\section{Teaching Approach related:}

1. On real patients, 2. On Teaching associates, 3 . On video , 4.On Mannequin (Simulator)

\section{Components Of Dre Skill ${ }^{10}$}

1. History Taking Skill- includes a. SelfIntroduction, Taking Consent, Establishing Rapport, Washing hands, Putting gloves, Privacy and Comforting patient.

2. Inspection Skill-includes Positioning of patient and legs, Perineum for identifying soiling, Anal fissure, Anorectal Fistulae, Anal growth, Prolapsed piles, Prolapsed rectum.

3. Palpation Skill- includes palpating Anusverge, Rectum: Cavity, Mucosa, Wall, Prostate: Side to side, Trying to reach above, Overlying Mucosa, Consistency, Tenderness,

Nodularity, Hardness, Median Sulcus, Lateral Sulcus.

4. Disease Diagnostic Skill- Features Diagnostic of Normal and Disease in DRE.

\section{Features Diagnostic of Normal \& Disease In Rectum \& Prostate during DRE ${ }^{11,12,13}$}

(A). DRE features diagnostic in disease in rectum

(A1).Masses or ulcer in wall of rectum- mass is arising from Within/Outside rectal wall.

(A2). Mass: Felt in lumen of Rectum

(A3). Mass in Recto vesical and recto uterine pouch

(A4). Bimanual recto-abdominal examination: for size, shape, nature of pelvic masses.,

(B). DRE features diagnostic of rectum tumour

(B1). Adenoma of rectum : Pedunculated or Sessile, Small or Large .

(BII). Cancer-tumour low rectum(ampulla): Whole lesion : fixed or mobile; with and without local spread.;
Papilliferous cancer: soft, frond like, narrow pedicle ;Villous cancer: Impalpable, sessile, soft ; Cancer ulcer: feels hard and bulges into lumen of rectum; Edge everted, Base irregular and friable

(BIII). Cancer-tumour upper rectum : May feel only lower edge of lesion in upper rectum; if patient strains down $2 \mathrm{~cm}$ of the lesion may become palpable.

(C). DRE features diagnostic of prostate tumour 4

(C1). Normal features :Prostate Gland's Surface is spread 2-3 cm across posterior wall of rectum, Smooth, Rubbery, Symmetrical Bilobed. Rectal mucosa- freely mobile, Median grove or sulcus- shallow : Normal Seminal Vesicle usually not palpable.

(CII). BPH : Prostate gland is smooth surfaced, mucosa mobile, asymmetrical bilobed., enlarged., Rubbery.; Median groove (Central sulcus)- last to disappear in BPH. Prostate gland when hypertrophied bulges in rectum in $\mathrm{BPH}$.

(CIII). Cancer prostate : - Prostate gland is Irregular, Hard, Asymmetrical often unilateral: Edges of gland indistinct, Mucosa may be fixed. Median groove (Central Sulcus) in Ca Prostate- may be distorted or obliterated at early stage of disease.

\section{Material and Method}

\section{Objective of Study:}

To assess

1. Experience of clinical training for DRE with focus on Reasons for not doing DRE, opportunity, supervision.

2. Awareness and Knowledge of Steps of DRE

3. Communication skill for (a). Ethics and Manners for Intimate physical examination DRE with focus on Consent-privacy-positioning and (b). History taking.

4. Disease diagnosis skill during DRE related to Anus: fissure- fistula- piles and Rectum: Polyp- Cancer.

5. Disease diagnosis skill during DRE related to Prostate : BPH and Cancer .

Study Design: Questionnaire-Based Research 


\section{Study}

A structured self-completion questionnaire ,as follows, related to DRE was given to Medical Students. They were asked to describe and Choose the correct outcome measure.

1. Perceived barriers to DRE; Socio Ethics related, Patient related, Medical Student related, Teaching Approach related

2. Attitude to DRE: Extent of unease felt?: Did not perform DRE/ Hesitant/ Guilty feeling/ Confident

3. Level of consent? : No consent/ Verbal / Written

4. Number of DREs performed; Degree of supervision?: No supervision/ Supervision Consultant

5. DRE performance by Medico: History Taking Skill, Inspection Skill, Palpation Skill, Disease Diagnostic Skill.

6. Diagnostic capability of Medico for diseases of Anus \& Rectum; Diagnostic Accuracy?:

7. Diagnostic capability for diseases of Prostate. Diagnostic Accuracy?

8. Confidence Level?: Unconfident/ Fully Confident

\section{Results}

Studies on digital rectal examination skill related Experience and attitudes among final year medical students : Saudi Arab and Indian Experience

1. MBBS Final Year students total 103 Males and 87 Females of medical schools in Kingdom of Saudi Arabia and India Participated in the study.

The break up was as follows: Males 36 only (Year 2015-16,Kingdom of Saudi Arabia); 34 Males and 40 Female (Year 2016-17 ,Kingdom of Saudi Arabia);

Males 17 and Females 23 ( Year 2017-1817 at NCR, India); and 16 Males and 24 Females(Year 201819 at NCR, India.)

2. Experience with DRE was done in

a. Present series by $65 \%$ Male and $72.41 \%$ Female Medicos. b. Reason for not doing DRE in most cases was sense of Bothersome, Opposite Sex examination and Sense guilt.

3. Skill evaluation- Awareness and Knowledge of Steps of DRE was present in Present series in $77.67 \%$ of Male and $86.49 \%$ of Female medicos.

a. DRE was done in present series 1 to 2 times by $90.3 \%$ of Male and $94.25 \%$ Female medicos .

b. DRE under Supervision was done in present series by $65 \%$ male and $72.41 \%$ female medicos .

4. Communication skill for Ethics \& etiquetteand manners was studied

a. Introduction with patient $75 \%$ males, $57.47 \%$ female medicos; for Consent taking before intimate examination by males in $45 \%$ and Females $57.47 \%$; for Privacy maintenance during intimate clinical examination by $45 \%$ male and $57.47 \%$ female medicos; proper positioning of patient was done by $81.55 \%$ male and $78.16 \%$ by female medicos.

b. History taking- related to diseases of AnusRectum- Prostate in present series was evident in $81.55 \%$ Male and $79.31 \%$ female medicos.

5. Disease diagnosing skill for Ano-Rectal benign conditions in present series was present in $92.2 \%$ Males and $94.25 \%$ female medicos and ; for Ano-Rectal malignant conditions in present series was present in $76.94 \%$ Males and $62.06 \%$ female medicos.

6. Disease diagnosing skill for Prostate benign hyperplasia in present series was present in $60.47 \%$ male and $54.49 \%$ female Medicos; for Prostate cancer in present series was present in $61.35 \%$ Male and $57.47 \%$ female medicos .

\section{Discussion}

1. DRE was done in Present series by $65 \%$ Male medicos and $72.41 \%$ Female Medicos against $83 \%$ Medicos reported by Turner KJ5.

2. Awareness and Knowledge of Steps of DRE

a. in present series DRE was done 1 to 2 times by $90.3 \%$ of Male and $94.25 \%$ Female medicos against 5 or less times by $32.78 \%$ DRE /month \& >10DRE times by $11.28 \%$ by Damien and Bolton. 14 
b. under Supervision was done in present series by $65 \%$ male and $72.41 \%$ female medicos against $31 \%$ in UK and 52\% in Australia. Damien and Bolton. 14

3. Communication skill for Ethics and Etiquettes was followed in present series for

a. Introduction with patient $75 \%$ males, $57.47 \%$ female medicos; for Consent taking before intimate examination by males in $45 \%$ and Females $57.47 \%$; for Privacy maintenance during intimate clinical examination by $45 \%$ male and $57.47 \%$ female medicos; proper positioning of patient was done by $81.55 \%$ male and $78.16 \%$ by female medicos.

b. History taking- related to diseases of AnusRectum- Prostate in present series was evident in $81.55 \%$ Male and $79.31 \%$ female medicos.

4. Disease diagnosing skill for Ano-Rectal benign conditions in present series was present in $92.2 \%$ Males and $94.25 \%$ female medicos and ; for Ano-Rectal malignant conditions in present series was present in $76.94 \%$ Males and $62.06 \%$ female medicos against $19 \%$ reported by Turner KJ5, in Oxford University Medicos $45 \%$ and in London University Medicos in 53\% as reported by Damien Bolton.14

5. Disease diagnosing skill for Prostate benign hyperplasia in present series was present in $60.47 \%$ male and $54.49 \%$ female Medicos; for Prostate cancer in present series was present in $61.35 \%$ Male and $57.47 \%$ female medicos against $24 \%$ reported by Turner KJ.5

\section{Conclusion}

1:MBBS Final Year students total 103 Males and 87 Females of medical schools in Kingdom of Saudi Arabia and India Participated.

The break up was as follows: Males 36 only (Year 2015-16 ,Kingdom of Saudi Arabia); 34 Males and 40 Female (Year 2016-17 ,Kingdom of Saudi Arabia);

17 Males and 23 Females ( Year 2017-1817 at NCR, India); and 16 Males and 24 Females(Year 2018-19 at NCR, India.)

2: Skill under evaluation- Knowledge of Steps of DRE-Male -77.67\% ; Female -86.49\%; Times attended training-Male nil times - $10.67 \%$; Male 1-2 times- 90.3\% // Female Nil times-5.74\%;
Female 1-2times -94.25\%; Times practised under Supervision-Male nil-36.89\%; Male 1-2times$65.0 \% / /$;Female nil times-27.58\%; Female 1-2times $-72.41 \%$

3: Communication skill(ethics \& etiquetteIntroduction-Male $75.72 \%$, Female $47.12 \%$; ConsentMale 45.63\%; Female 57.47\% ;Privacy-Male $45.63 \%$ , Female 57.47\%; Position-Male $81.55 \%$; Female $78.16 \%$

4: Communication Skill(History Taking)- GI Anus, Rectum History: Bleeding, Pain, Discharge- Male 81.55\%; Female $79.31 \%$

5: Disease diagnostic skill - Anus, Rectum : Fissure, Fistula, Prolapse: Male (92.23\%) \& Female (94.25\%);

Rectum Polyp-: Male (92.23\%) \& Female (94.25\%); Cancer Rectum-: Male (76.94\%) \& Female (62.06\%)

6: Disease diagnostic skill- prostate: BPH- Male (60.47\%); Female (54.49\%); PROSTATE CANCERMale (61.35\%) Female (57.47\%)

Conflict of Interest: No Conflict Of Interest.

\section{Source of Funding: Self-Funding}

Ethical Clearance: The ethics review was not considered in this study to require approval. Informed consent was obtained prior to the SP training. The participation was voluntary. All participants gave written informed consent

\section{References}

1 Browse N. An introduction to the symptoms and signs of surgical disease. London: Edward Arnold, 1991: 415-418.

2 Makinen T, Tammela TL, Hakama M, et al. Prostate cancer screening within a prostate specific antigen range of 3 to $3.9 \mathrm{ng} . / \mathrm{ml}$.: a comparison of digital rectal examination and free prostate specific antigen as supplemental screening tests. J Urol 2001; 166: 1339-1342.

3 Carvalhal GF, Smith DS, Mager DE, et al. Digital rectal examination for detecting prostate can- cer at prostate specific antigen levels of $4 \mathrm{ng} / \mathrm{ml}$ or less. $J$ Urol 1999; 161: 835-839.

4 Dixon AR, Thornton-Holmes J, Cheetham NM. General practitioners' awareness of colorectal 
cancer: a 10 year review. BMJ 1990; 301: 152- 153.

5 Turner KJ, Brewster SF. Rectal examination and urethral catheterization by medical students and house officers: taught but not used. BJU Int 2000; 86: 422-426.

6 Hennigan TW, Franks PJ, Hocken DB, AllenMersh TG. Influence of undergraduate teach- ing on medical students' attitudes to rectal examination. BMJ 1991; 302: 829.

7 Peyton JW(1998): Teaching and learning in Medical Practice. Heronsgate Rickmansworth, Herts: Manticore Europe Ltd,1998 - Google Scholar

8 Coldicott Y, Pope C, Roberts C. The ethics of intimate examinations - teaching tomorrow's doctors. BMJ 2003; 326: 97-101.

9. Popadiuk C, Pottle M, Curran V. Teaching digital rectal examinations to medical students: an evaluation study of teaching methods. Acad Med 2002; 77: 1140-1146.

10 Hicks LK, Lin Y, Robertson DW, et al. Understanding the clinical dilemmas that shape medical students' ethical development: questionnaire survey and focus group study. BMJ 2001; 322: 709 710.

11 Johnston JM, Leung GM, Fielding R, et al. The development and validation of a knowledge, attitude and behaviour questionnaire to assess undergraduate evidence-based practice teaching and learning. Med Educ 2003; 37: 992-1000.

12. Baily \& Love's Short Practice of Surgery: 26 Edition 2013, 1215-18, 1340-50.

13. Schwartz's Principles of Surgery, 8th Edition 2005, 1062-63, 1535-36

14 Sabiston's Textbook of Surgery: $19^{\text {th }}$ Edition 2013, Vol 2 : 1322-23

15 Nathan Lawrentschuk and Damien M Bolton : Experience and attitudes of final-year medical students to digital rectal examination ; MJAOctober 2004 - The Medical journal of Australia; Volume 181 Number 6

16. Hennigan TW, Franks PJ, Hocken DB, AllenMersh TG. Rectal examination in general practice. BMJ 1990; 301: 478-480. 